Journal of Engineering and Applied Sciences 15 (2): 535-547, 2020

ISSN: 1816-949X

(C) Medwell Journals, 2020

\title{
A Review on Smart Energy Grid Technology: Features and Specifications
}

\author{
${ }^{1}$ Moamin A. Mahmoud, ${ }^{1}$ Alicia Y.C. Tang, ${ }^{1}$ Andino Maseleno, ${ }^{2}$ Fung-Cheng Lim, \\ ${ }^{2}$ Hairoladenan Kasim, ${ }^{3}$ Christine Yong and ${ }^{4}$ Salama A. Mostafa \\ ${ }^{1}$ Institute of Informatics and Computing in Energy, Universiti Tenaga Nasional, Kajang, Malaysia \\ ${ }^{2}$ College of Computing and Informatics, Universiti Tenaga Nasional, Kajang, Malaysia \\ ${ }^{3}$ ICT Division, Tenaga Nasional Berhad, Kuala Lumpur, Malaysia \\ ${ }^{4}$ Faculty of Computer Science and Information Technology, Universiti Tun Hussein Onn Malaysia, \\ Parit Raja, Malaysia
}

\begin{abstract}
Although, it is widely recognized that smart grid technology is a necessity to reduce the impact of global warming while encouraging efficiency, reliability and effective governance in the supply of electrical energy, the understanding of smart grid technology among researchers is limited. To provide a clear insight to this problem and support researchers, we need a background understanding of various aspects related to smart grid. Current electricity transmission and distribution networks can be categorized as conventional electricity networks because they have not been able to provide excellent service and present real-time data. This network has not been able to provide reliability, safety and efficiency in supplying electrical energy even not yet have the flexibility to be integrated with the generation of renewable energy or microgrid. In this study, a comprehensive review is conducted to map the literature studies to a coherent taxonomy. These include the features and specifications of smart grid. The fundamentals of smart grid presented in this study can benefit readers who wish to embark in smart grid research and applications development.
\end{abstract}

Key words: Smart grid, power system, renewable energy, internet of things, literature, fundamentals

\section{INTRODUCTION}

A smart electrical network or better known as smart grid is one form of transformation and technological reform in the electricity industry. A smart grid is a modern electrical energy network that intelligently integrates power grids with communications devices that support electricity generation and distribution networks to be more attractive, communicative and qualified. A smart grid is a modern electric grid concept that has a high degree of flexibility, accessibility and efficiency. In the smart grid network is spread digital sensors, smart meter, online monitoring, automation equipment and two-way communication system that allows between operator and consumer interact each other, so as to improve reliability in service compared with the existing power system. Smart grid is an integrated and interdisciplinary power grid technology concept that is still being developed. The Telegestore project is the first power grid to use smart meters on its 27 million subscribers which are connected using low-bandwidth communication technology power line communication.

The Telegestore project is located in Italy and began in 2005. Telegestore is claimed to be the world's first smart grid technology that caters to residential scale. This smart grid technology has great potential for tremendous energy savings. A revolution in electricity network technology of the world.

Smart grid consists of 3 important elements, namely information technology, telecommunication and electric power. All three elements work together to enable two-way communication between the electricity provider and the consumer. With smart grid, the transfer of electrical energy happens not only from the provider of electricity to the consumer but also vice versa. If it turns out consumers that have solar cells can generate electrical energy from sunlight, so when the electrical energy from the solar cell is greater than the needs of consumers, the consumer can send electrical energy to the existing grid. Consumers can get money from the utility company for that matter.

To provide a clear insight to this problem and support researchers, we need a background understanding of various aspects related to smart grid. Current electricity transmission and distribution networks can be categorized as conventional electricity networks because they have not been able to provide excellent service and present real-time data. This network has not been able to provide reliability, safety and efficiency in supplying electrical energy even not yet have the flexibility to be integrated with the generation of renewable energy or microgrid. In

Corresponding Author: Moamin A. Mahmoud, Institute of Informatics and Computing in Energy, Universiti Tenaga Nasional, Kajang, Malaysia 
this study, a comprehensive review is conducted to map the literature studies to a coherent taxonomy. These include the features and specifications of smart grid. The fundamentals of smart grid presented in this study can benefit readers who wish to embark in smart grid research and applications development.

\section{MATERIALS AND METHODS}

Smart energy grid: Smart Grid is a modern electric grid concept whose planning, development and research have developed rapidly (Amin and Wollenberg, 2005; Gungor et al., 2010). Some countries in the USA and Europe have been very intensive to realize the technology. In the USA the smart grid implementation is coordinated by the Department of Energy (DOE) together with EPRI (Electric Power Reserach Institute) with its project called "Intelligent grid" (Haase, 2009). This project develops communication process between power grid with computer to improve reliability of power system and service to consumer. In addition DOE also affiliates with the industry sector through the grid wise program. The focus of this program is to define the communication design and smart grid standard, simulation and analysis tools, smart technology, test and demo plant infrastructure, legal protection and market framework. Meanwhile, smart grid European Technology Platform (ETP) has a vision that power system networks in Europe must be flexible in meeting consumer needs, accessible, reliable and economical (Gungor et al., 2011). To realize that vision the main requirements include creating a technical solution that can be applied in a cost effective way, so as to accept the integration of all sources of electrical energy harmonizing regulations and facilitating cross-commercial structures in Europe in the service of electrical energy issuing technical regulations and standards developoing an IT-based system ensuring the successful integration of the old system design with the new system. Until now, there is no mutual decision on the definition of smart grid.

Each country and research institute of the world defines smart grid differently but generally has the same framework. According to NIST smart grid can be defined as a network of electrical power systems that use two-way information technology, secure cyber communications technology and intelligence computing integrated across the spectrum of electrical energy systems ranging from generators to consumers. The anticipated benefits and requirements of SG are the following (NIST., 2010) Improving power reliability and quality optimizing facility utilization and averting construction of back-up (peak load) power plants enhancing capacity and efficiency of existing electric power networks improving resilience to disruption enabling predictive maintenance and self-healing responses to system disturbances facilitating expanded deployment of renewable energy sources accommodating distributed power sources automating maintenance and operation reducing greenhouse gas emissions by enabling electric vehicles and new power sources reducing oil consumption by reducing the need for inefficient generation during peak usage periods presenting opportunities to improve grid security enabling transition to plug-in electric vehicles and new energy storage options increasing consumer choice enabling new products, services and markets.

While the smart grid according to the Department of Energy (DOE) USA is a power system based on sensing technology, communication, digital control, Information Technology (IT) and other field equipment that serves to coordinate the existing processes in the power grid making it more effective and dynamic in its management. The feasibility and reliability of the power supply is one of the vital parameters in energy distribution, especially, for cross-application or operator. The information available in each generator, transmission and distribution area is usually only for each local power grid and system data is not based on real time data. This is the challenge for the future, so that, the power grid can be more qualified with a high level of reliability as well safe from interference. The inefficiency of existing systems is one of the things which encourages the presence of smart grid paradigm. The general comparison between the current power system and the smart grid is shown in Table 1. Figure 1 shows the review of literature on smart energy grid features and specifications.

Smart grid features: Environmental destruction that is marked by high $\mathrm{CO}_{2}$ level or greenhouse gas emissions due to excessive use of fossil fuels is a serious challenge that must be minimized immediately. One of the most prominent impact is the destruction of natural ecosystems such as forest fires due to very high temperature, rising sea level, flash flood, melting of iceberg in the north and south poles and uncertain natural climates. From the energy sector that contribute most to global warming is the power generation sector. Currently there are still many power plants that use fossil fuels such as petroleum and coal as the main source of turbine drive in generating electrical energy. The burning results certainly produce $\mathrm{CO}_{2}$ gas that contributes to increase levels of global warming. In response to the crucial issue, developed countries make an effort to reduce the impact of greenhouse gases by conducting research and utilization of renewable energy as an environmentally friendly source of energy such as wind energy and solar energy. Renewable energy is capable of generating electrical energy without generating and increasing greenhouse gases. Current renewable energy utilization trends continue to increase which contributes to the birth of the smart grid concept.

Smart grid is a modern electrical energy network that intelligently integrates power grids with communications devices that support electricity generation and distribution networks to be more attractive, communicative and qualified. The term grid is used for an electricity system 


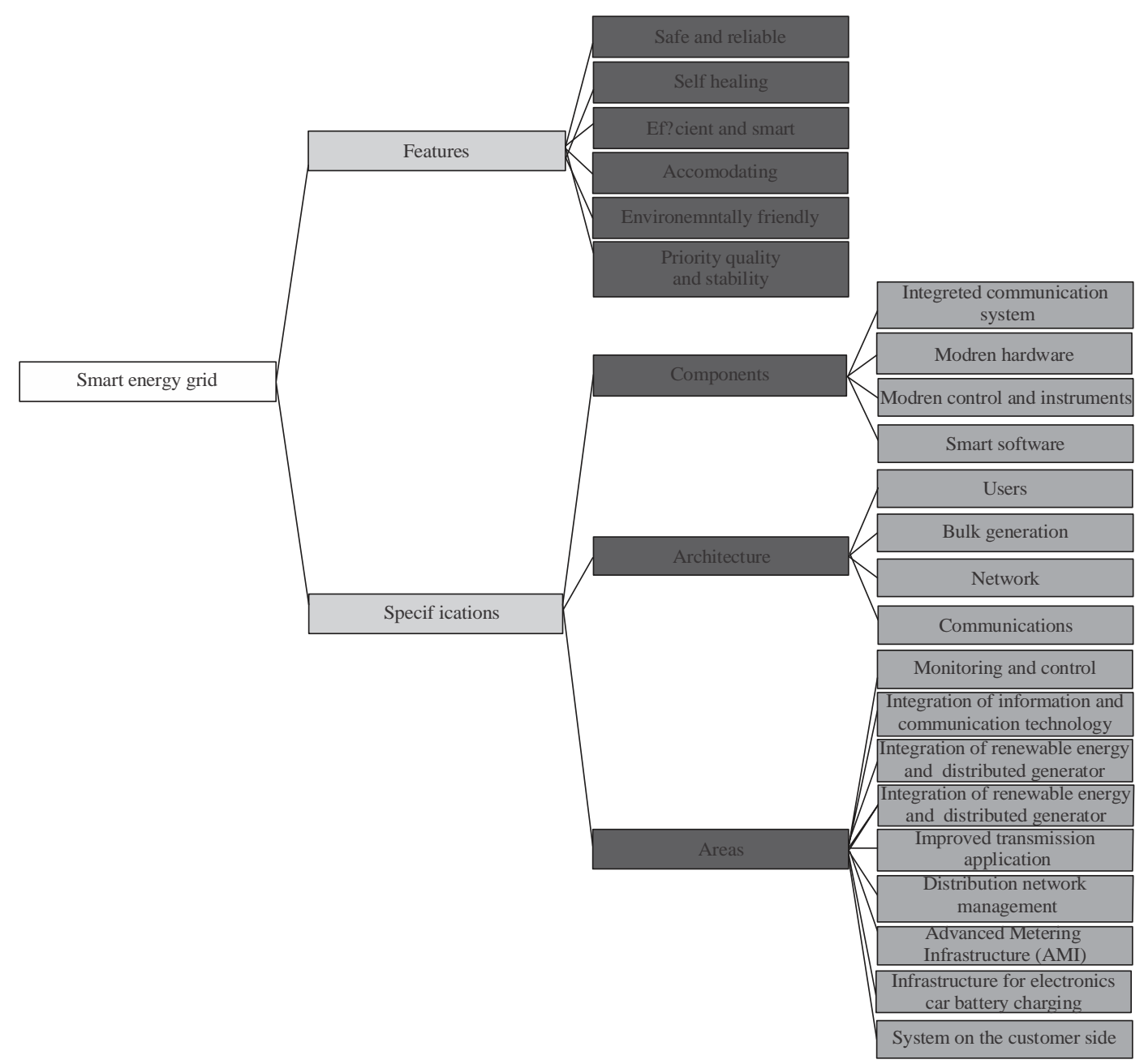

Fig. 1: Taxonomy of literature on smart energy grid implications and implementation

Table 1: The general comparison between the current power system and the smart energy grid

\section{Power system}

Centralized generation. Dominated by central

generation-many obstacles exist for distributed

energy resources interconnection

Electro mechanical

One-way communication

Small number of sensors

Manual monitoring

Manual restoration. Responds to prevent further damage-focus is on protecting assets following fault

Failures and blackouts

Limited control

Few consumer choices. Consumers are uninformed and non-participative with energy system

Limited wholesale markets, not well integrated-limited opportunities for consumers

Little integration of operational data with asset

management-business process silos

Vulnerable to malicious acts of terror and natural disasters

\section{Smart energy grid}

Distributed generation. Many distributed energy resources with

plug-and-play convenience focus on renewables (Dibangoye et al., 2015;

Jarrah et al., 2015)

Digital (Mei in 2013)

Two-way real time communication (Gao et al., 2012)

Many sensors and monitors (Kilic and Gungor, 2013; Wang et al., 2015)

Self-monitoring (Sendin et al., 2013; Grzonka et al., 2014)

Self healing. Automatically detects and responds to problems-focus on

prevention, minimizing impact to consumer (Dahal et al., 2015)

Adaptive and islanding

Pervasive/extensive control system (Kim et al., 2015; Evora et al., 2015;

Ahn and Peng, 2013; Jarventausta et al., 2010)

Many consumer choices. Informed, involved and active

consumers-demand response and distributed energy resources

(Gangale et al., 2013; Goulden et al., 2014)

Mature, well-integrated wholesale markets, growth of new electricity markets for consumers (Siano, 2014; Aghaei and Alizadeh, 2013)

Greatly expanded data acquisition of grid parameters focus on prevention, minimizing impact to consumers (Deilami et al., 2011; Ling and Massao, 2011)

Resilient to attack and natural disasters with rapid restoration capabilities (Liu et al., 2013). 
that may support all or some of the following four operations: electricity generation, electricity transmission, electricity distribution and electricity control. Smart grid will be a main key in the transformation process in the electrical energy sector because of several benefits, among others.

Safe and reliable: High-level cyber security becomes one of the most important parameters for safe and reliable smart grid (Gharavi and Ghafurian, 2011). Smart grid-based communication and protection system which is IT-based is very prone to hacker attacks and also natural disturbances. But by adopting sophisticated encryption security system and multi layer then cyber attack and other interferences s can be prevented. The possibility of disturbance due to natural factors will also be possible detected earlier with weather sensors that can provide weather reports in real time. Protection system is also more reliable because it is auto maintenance and auto repair thereby reducing the length of repair time in case of interruption in power grid.

Self healing: Self-healing is a term used to describe the ability of the power grid to detect to predict to anticipate and to respond to disturbances that occur in the system quickly based on data or information transmitted by the sensors that have been installed (Farhangi, 2010). For example when there is a disruption to the transformer the protection system will automatically isolate the interference without waiting for the operator to come to the location of the interference, so as not to interfere with other networks and not cause blackouts in the surrounding network.

Efficient and smart: Each domain in the smart grid that includes generators, transmission, distribution and consumer will be equipped with Advanced Sensor Insfrastructures (ASI) that serves to provide specific parameters data in the smart grid network in real time desired (Momoh, 2009; Bu et al., 2012). With these data, the operator can minimize the occurrence of interference such as overload (overload) that can cause total blackout.

Accomodating: Smart grids will be more flexible to be integrated with power generation from renewable energy such as solar energy generation and wind energy in the form of micro grid (Wang et al., 2010; Kanchev et al., 2011). Smart grid is also more accommodating to scattered small scale power plants (distributed generation and micro grid) (Battaglini et al., 2009).

Environemntally friendly: It is possible that the integration of large scale renewable energy-based micro power generation makes smart grid very environmentally friendly (Aghaei and Alizadeh, 2013). Utilization of renewable energy will reduce the impact of greenhouse gases thereby driving the decline of global warming (global warming).

Priority quality and stability: Smart grid will be more focused in maintaining the quality of power (power quality) in the supply of electrical energy. Problems that harm consumers and providers of electric energy can be reduced to the fullest. The problem usually occurs because of unstable voltage, rise and fall of frequency and the emergence of harmonics.

In the smart grid network there are several digital devices such as collector and recording data, automation, sensor, smart meter, real time data display, data management and two-way communication applications added in the power grid from generator to consumer. So that, the electrical network system becomes more complex, especially, in terms of data communication and coordination between sensors. To overcome this, the system requires the integration of information technology and processor data that is adequate in all domains of the power network.

Figure 2 is an Intelligrid model designed by Electrical Power Research Institute's (EPRI's). In the network installed smart grid technology includes the system of dynamic control, data management, Advanced Metering Infrastructure (AMI), internet communications system, plug-in hybrid cars, energy storage, distributed generation and portals consumers for energy management as well as smart devices for end consumers. From a series of infrastructure installed throughout the power grid sector in Fig. 2, the main foundation is the availability of a wide range of intelligent sensor, integrated information and communication technologies between consumers and the power grid. With these technologies, raw data sent by the sensor through fiber optic cable, wireless and internet can be processed, transferred and analyzed when it is in the data center for further feedback. One of the technologies that will become the backbone of smart grid implementation is information and communication technology. Internet of Things (IoT) is a network of sensors and sensors that process information consisting of Radio Frequensi Identification (RFID), infrared sensor, Global Positioning System (GPS), lasser scanner and internet.

Components of smart grid: A smart grid intelligently integrates the activities of all users/customers (power plants, customers) in order to provide/to produce electricity efficiently, sustainably, economically and securely. Smart grid uses innovative products and together serve with monitoring, control, communication and self- healing technologies to: 


\section{J. Eng. Applied Sci., 15 (2): 535-547, 2020}

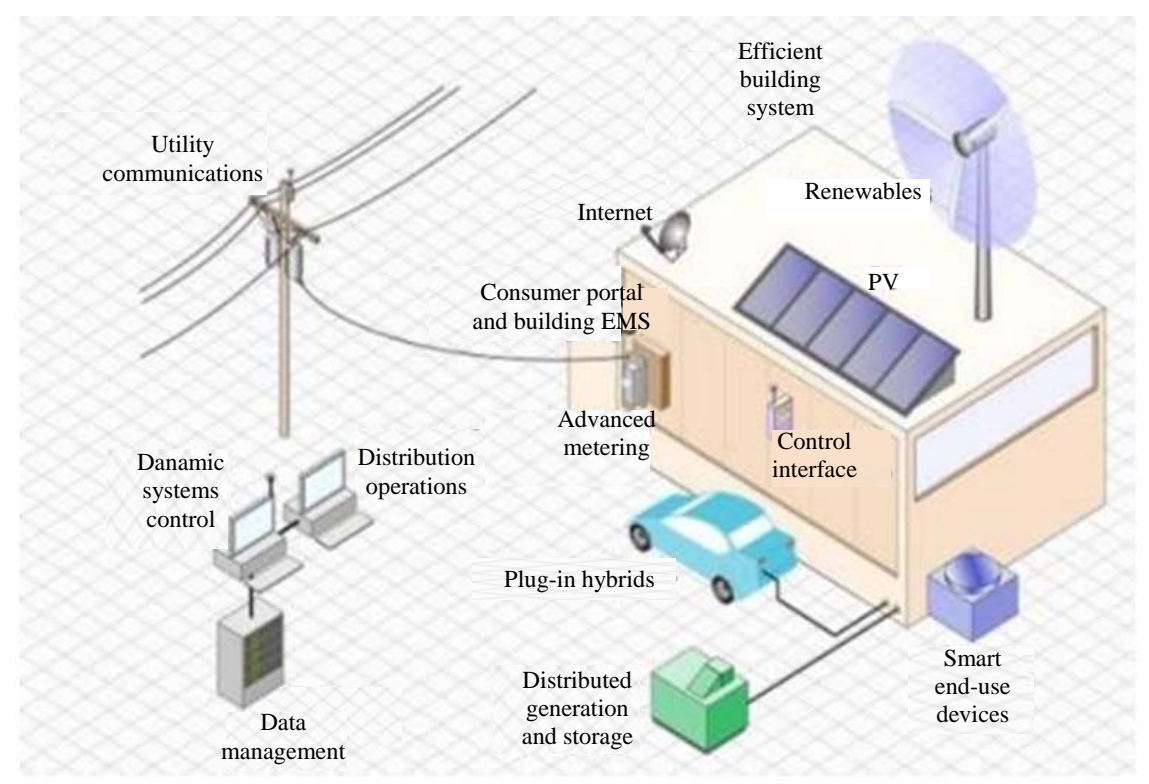

Fig. 2: Smart grid model and scenario by EPRI

- Facilitate better relationships and operations of all generators and technologies

- Provide flexibility to customers and to determine part of optimization of the operation of the system

- Provide customers with information and options for supply

- Significantly reduce the environmental impact of the entire power supply system

- Improve reliability and safety of supply

The smart grid is the management of electrical energys with integrated concepts and reduces the dependence on natural resources derived from fossils. This integration enables communication and information exchange between electricity generation, distribution and consumption to make smarter decisions about energy consumption and production. In the smart grid there are 3 elements of technology that is electric power technology, information and telecommunications. The three units are integrated with each other, allowing two-way communication between power companies such as Tenaga National Berhad and consumers. The transfer of electrical energy in the smart grid is unlike conventional systems that are only one way but can also be done otherwise. If it turns out consumers have their own electrical energy sources such as solar panels that can generate electrical energy from sunlight, then when the electrical energy generated is excessive then the consumer can send the resulting electrical energy to the existing grid. From that consumers are not only pay utility bills alone but also can make money from generated electricity.
The smart grid consists of communication networks, advanced sensors and control tools that serve to monitor the running of the system. The received power current and power consumption used will be in data and control in real time, hence from that power current need to be controlled in order to get optimal and efficient network performance. Therefore, it is necessary to set up a device on the network that can monitor the flow of two-way communication and information between the power plant, the control base and the consumer. Regulatory methods in this system are obtained based on data collected on the control base that receives data from sensors that monitor energy consumption in real time, weather conditions, operating status, equipment conditions and energy availability of power plants and energy owned by consumers. The data then will be used to predict energy and energy needs that will be channeled to consumers. In addition, the data obtained will be used as a control grid which requires more energy. On smart grid if the source of electrical energy from one power plan can not distribute electrical energy, then the source of electrical energy can be diverted and disitribusikan from other sources. Smart grid parts consist of an integrated communication system, modern hardware, modern Control and Instrumentation (I\&C) and smart software parts. Below will be described each section.

Integrated communication system, this component allows communication to occur two-way between base control, consumer and power plant and can be fully integrated, so that, the system is dynamic and inteactive to exchange data and power in real time. The system in 
this section is copper wiring, fiber optic, power line carrier, wireless technology and broadband over power line technologies.

Modern hardware in this part of the hardware system that supports smart grid system must use good materials, good super conductive materials, parts on power plan such as inverters, turbines and so on to support the availability of energy source. In addition the most important part is the battery used that can store electrical energy to be used next time.

Modern Control and Instrumentation (I\&C) in this section consists of algorithms to control the system to run properly by working to analyze to diagnose and to predict the needs of electricity and the availability of electricity in accordance with the incident that is happening. Examples of this system are the use of SCADA, sensors, digital relays and smart meters.

Smart software in this part the use of software that can work in real time, dynamic, fast and accurate to make consumers comfortable and easy to use it.

Architecture of smart grid: In the application of a smart grid system usually consists of users, bulk generation, network, coomunication.

Users (customer): Smart consumption will permit reaction to interface need between distribution management and building automation. Local production is currently not a major component but local production is expected to be the future referrer of the smart grid requirement.

A smart home is home equipped with automation systems. The home automation system incorporates a variety of controls for lighting, shutter, temperature control and other equipment to enable efficient, economical and increased the comfort energy use.

Building automation and control systems (BACS = Building Automation and Control System) is the brain of the building. BACS incorporates instrumentation, control and management technology for all building structures, plants, outdoor facilities and other equipment.

Bulk generation: Smart generation will include the increased use of power electronics in order to control harmonics, fluctuating generation failures from renewable energy as well as the need for increased flexibility of fossil power plants due to increased fluidation from renewable energy sources.

Network (transmision dan distribution): Automation of substation and protection is the backbone for the operation of a secure transmission network. Power quality and power monitoring systems act similarly to a company's quality management system. They are free from operating systems, controls and management and supervise all electrical activities and equipment in the same network. Therefore such a system can be used as an early warning system and must analyze failure and find suitable grounds. The Energy Management System(EMS) is the control center for the transmission network. Customers now require open architecture to allow easy IT integration and better backups to avoid blackouts. Power electronics are among the actuators in the power grid. Systems such as HVDC and facts allow control of the power flow and can help to increase transport capacity without short-circuit increases.

Distribution Management System (DMS) is the control center for power grids. In a country where outages is common constraints, the Outage Management System (OMS) is an important component of DMS. Another important component is the location of failures and interface on Geographic Information Systems (GIS). Smart meter is a generic term for an electronic meter with a communication link. Advanced Metering Infrastructure (AMI) provides remote measurement configurations, dynamic rates, power quality monitoring and load control. More advanced systems integrate infrastructure measurement with distribution automation.

Communication: Communication as a whole is the backbone of the smart grid. Only by exchanging information at the syntactic and semantic levels of smart grid benefits can be achieved.

The security of critical infrastructure has always been a major issue. But the smart grid solution will encounter a huge increase in data exchange for observation capabilities and also for control. Therefore, the security of this data exchange and the components behind it will have a better impact.

Areas of smart grid: Smart grid technology area (each with individual technology) across a whole network range from multiple generation through transmission and distribution to various types of electricity customers. A number of technologies are actively utilized and considered established for their development and application while others still require further development and demos. A fully optimized electrical system will be deployed across all technological areas. But not all technologies need to be installed to improve the intelligence of the network.

\section{RESULTS AND DISCUSSION}

Monitoring and control area: Real time monitoring and display of power system components and performance, along the connection and in large geographic areas, helps operators to understand and to optimize the behavior and performance of power system components. Advanced 


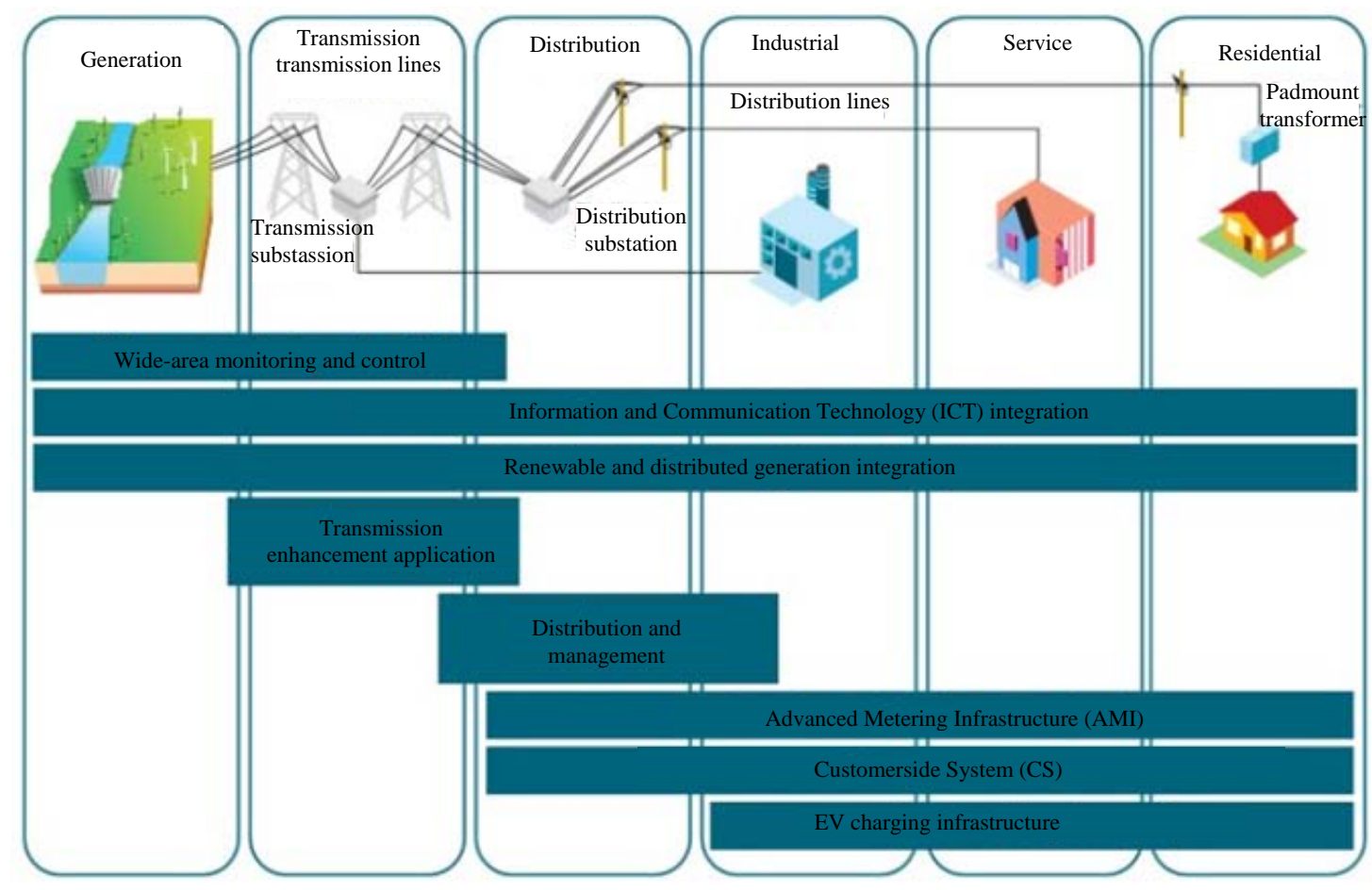

Fig. 3: Technology about smart grid

operating equipment system avoids blackout and facilitates the integration of renewable energy sources. Technology about smart grid can be seen in Fig. 3

Integration of information and communication technology: Communications infrastructure needs to be prepared using either a private network (radio network) or public network operator (internet, cellular, cable or telephone) communications utility (Rohjans et al., 2012). Along with communication devices, computing, control system software and software, it is necessary to plan enterprise resources to support the exchange of two-way information between stakeholders enabling the use and management of a more efficient network.

Integration of renewable energy and distributed generator: The integration of large-scale renewable technology, distributed energy resources which cover large scale in transmission, medium scale in distribution level and small scale in commmercial or settlement can be a challenge for the delivery and control of these resources and for the operation of electrical systems. Energy storage systems, both electric and thermal (themal) can alleviate problems such as production coupling and energy delivery. Smart grids can help by automating control of generation and demand (in addition to demand response forms) to ensure supply and demand balance.
Improved transmission application: There are several technologies and applications for transmission system. Flexible AC Transmission System (FACTS) is used to improve the control of the transmission network and maximize the power transfer capability. The deployment of this technology on the line can improve efficiency and delay additional investment needs. The DC High-Voltage technology (HVDC) is used to connect offshore wind power generators and centralized solar power plants with large electrical environments with loss reductions system and improved control systems, enabling efficient use of far energy source from the load center. The use of High Temperature Superconductors (HTS) can significantly reduce transmission losses and allow for higherperformance current delimiters, despite the debate over market-ready technology.

Distribution network management: Distribution and sub-station sensing and automation can reduce shutdown time and repair, maintain voltage levels and improve asset management. Advanced distribution automation processes real-time information from sensors and meters for fault location, automatic reconfiguration of feeder, stress and reactive power optimization or for control of distributed generation.

Advanced Metering Infrastructure (AMI): The advanced metering system which consists of electronic 
state of the art/digital hardware and software which combines data measurement intervals with continued long distance communication available. The system allows detailed measurement, time-based information and the collection and transmission of information to various parties. AMI usually refers to an overall measurement system and collection that includes a meter at a customer's location, a communications network between customers and service providers such as gas, electricity or water utilities and receipt of data and management systems that make information available to service providers.

This meter has the ability to transmit data collected through the commonly available fixed networks such as Broadband over Power Line (BPL), Power Line Communications (PLC), fixed Radio Frequency (RF) networks and public networks (e.g., cable, cellular, paging).

The meter data is received by the AMI host system and sent to the Data Meter Management System (MDMS) that manages data storage and analysis to provide information in useful forms for utilities. AMI allows two-way communication, so, communication from utilities to meters can also occur. AMI will provide consumers with the following functions:

- $\quad$ The price of a remote customer signal which can provide information on usage time

- Ability to collect to store and to report customer energy consumption for any required or near real time interval

- $\quad$ Increased energy diagnostics from a more detailed load profile

- Ability to identify the location and extent of a remote powered area via a metering function that sends a signal when the meter is out and when the power is restored

- $\quad$ Remote linking and disconnection

- Detection of loss and theft

- $\quad$ The ability for retail energy service providers to manage revenue through more effective cash collection and debt management

AMI technology provides the utility of ability to reduce the operating costs of its distribution system by automating various functions that are currently executed manually including reading customer meters and turning power on and off at customer meters. Utilities can also use AMI to help customers reduce their electricity usage when in an expensive power price system (peak hour).

In the smart grid, smart meter is not only functioned as a tool to measure consumer electricity usage per month only but enabled to do network monitoring use of automation on network and so forth. Therefore, smart meter system is enabled not only receive data from the use of electricity consumption but can send data, then the security system contained in this smart meter must be managed properly, so that, data sent from the consumer to the base control is safe and cannot be stolen by people who are not interested. Smart meter used in smart grid is Advanced Metering Infrastructure (AMI) which is an entire infrastructure of smart meter that manages two-way communication network to base control equipment (base control) and all applications that can do collection and delivery of information about energy use in real time. So, AMI can manage and control electrical parameters and other devices on the consumer grid and power plan. The devices used in AMI are meter device, sensors and controls and wireless devices that enable remote communication between the grid and base control.

Infrastructure for electric car battery charging: The electric vehicle battery charging infrastructure handles billing, scheduling and other smart features for smart charging (the vehicle grid) during low energy demand. In the long term, it is conceivable that large installation filling will provide additional power system services such as capacity reserves, peak load cuts and vehicle filling regulations on the network.

System on the customer side: Customer-side system which is used to help industry to manage electricity consumption, service level and housing including energy management systems, energy storage devices, smart equipment and distributed generator. Improved energy efficiency and peak load demand reduction can be accelerated from home with display or energy dashboards, smart equipment and local energy storage. The demand response includes user manual and automatic user response, price-responsive equipment and thermostats connected to an energy management system or controlled by signal from the operator or utility system.

\section{Future directions}

IoT technology: IoT technology is widely used for traffic monitoring, industrial processes, the military and the environment. The use of Internet of Things (IoT) in the power system network is the result of the development of information and communication technology (Baoyun, 2009; Li et al., 2011; Yun and Yuxin, 2010). Currently, the implementation of information and communication technology in the power grid is still very limited even in some place is still not exist. So that, the level of automatic is low. This has an impact on weak governance information on the power grid, especially, the simultaneous transmission and distribution networks also affects the decline in service to consumers. Although in some aspects of the level of automation is always made changes and improvements 
but still not able to meet the expectations, especially in context of smart grid. The current electrical network still has many loopholes or weaknesses in the network data communication system. For example in monitoring the quality of power in the network distribution, the operator must make a field visit to monitor the desired network, so that, the data obtained is not real-time.

Data communication patterns between network is also still one-way (one-way communication), so that, when the fault occurs (fault) repair period (recovery) is longer. Some equipment such as transformers is still isolated, so, they can not be monitored by online. The installed protection equipment is still electromechanical and not yet integrated with the digital sensor, so that, the information that can be received by the operator in the control room is very limited. Thus the level of intelligence throughout the existing power grid is still very low and not yet in the smart grid category. To make the existing power system becomes more intelligent it must be done by upgrading infrastructure such as the addition of digital sensor, auto protection system, online monitoring, wireless sensor network, measuring instrument, CCTV camera and other smart devices. The improvement of the infrastructure should adopt smart grid technology. However, the existence of these tools will not necessarily makes the system smarter without the application of IoT integrated in the power grid. IoT will facilitate the equipment to interact and to exchange data in realtime, so that, the communication pattern becomes two way (two-way communication).

In realizing the smart grid IoT is one of the main key that should be used in the power grid. IoT consists of 3 layers namely perception layer, network layer and application layer. Each layer has different roles and functions but still in the electrical grid. With these technologies, raw data is sent by the sensor through fiber optic cable, wireless and internet can be processed, transferred and analyzed when it is in the data center for further feedback. One of the technologies that will become the backbone of smart grid implementation is information and communication technology. Internet of Things (IoT) is a network consisting of various sensors and sensing devices that perform information processing consisting of Radio Frequensi Identification (RFID), infrared sensor, Global Positioning System (GPS), lasser scanner and internet.

IoT technology is widely used for traffic monitoring, industrial processes, military and environment. The use of Internet of Things (IoT) in the power system network is the result of the development of information and communication technology. Currently, the implementation of information and communication technology in the power grid is still very limited even in some places still have not existed at all. So, the level of automatic is low. This has an impact on the weakness of information governance in power grids, especially, transmission and distribution networks that simultaneously also affect the decrease of service to consumers. Although, in some aspects the level of automation is always changing and increasing the number but still not able to meet the expectations, especially in the context of smart grid. The current electrical network still has many loopholes or weaknesses in the network data communication system. For example in monitoring the quality of power in the distribution network, the operator must perform field visits to monitor the desired network, so that, the data obtained is not real-time. Data communication patterns between networks is also still one way (one-way communication), so that when there is a fault (fault) the repair period (recovery) is longer.

Some equipment such as transformer is still isolated, so, it cannot be monitored by online. The installed protective equipment is still in character of electro mechanical and not yet integrated with digital sensors, so that, information can be received by the operator in the control room is very limited. Thus the level intelligence throughout the existing power grid is still very low and not yet in the category of smart grid. To make the existing power system becomes more intelligent then should be done (upgrading) infrastructure such as the addition of digital sensors, auto protection system, online monitoring, wireless sensor network, measuring instrument, CCTV cameras and other smart devices. The improvement of the infrastructure should adopt smart grid technology.

However, the existence of these tools will not necessarily make the system smarter without the application of IoT integrated in the power grid. IoT will facilitate the equipment to interact and exchange data in realtime, so that, the communication pattern becomes twoway (two-way communication). In realizing the smart grid IoT is one of the main keys that should be used in the power grid. IoT consists of 3 layers of layers namely perception layer, network layer and application layer. Each layer has different roles and functions but is still in a continuous framework and integrated. Perception layer (perception layer) serves to perceive and to identify an object. It also serves to collect and capture information.

The perceptual layer consists of 2 dimensions of code tags and reader codes, RFID markers and readers, GPS, video camera or CCTV, smart sensor, network sensor, terminals or interfaces for machines to machine and gate way sensors. The perception layer is usually divided into two sub-layers: perception control sub-layer and communication extension sub-layer.

Subconscious perception controls embody the intelligent perceptions of the physical world including recognition, information acquisition, data processing and automatic control. Meanwhile the communications 
extension sub-layer is connected to a physical entity that can be connected to a network layer and application layer with the help of a communication module either directly or through multiple connecting terminals. The network layer consists of various types of communication networks (internet) and core networks. The network layer of communication is usually used as an access network. While the process of information transfer, routing and controlling information is done and implemented in the core network. The network layer can use special communications networks that are designed to suit the needs or can also use publicly available networks. The application layer is a combination of IoT technology with industry tools that aim to make the system a smarter solution.

The application layer covers all the infrastructure and devices used in the industry related to the IoT-based monitoring process. Applications in this layer will provide information processing, computing and data integration. So, security inside the process of data sharing becomes the primary subject of the concern in the application layer.

IoT in power system network to realize IoT in power system network then there are some important technologies that must be used in network generator, transmission, substation, distribution and end consumer.

Smart sensor technology: Sensor is the main tools placed on the infrastructure to be monitored. Sensor will provide information in real time in the form of good signal from analog to digital or vice versa (Gungor et al., 2010). The raw data will be processed, sent, analyzed and then given feedback. Example of smart sensor includes temperature sensors, light sensors, pressure sensors, heat sensors, power sensors, current sensors, motion sensors and so on. With the sensor then the data sent to the network layer and network applications can be more accurate and real time.

Information and communication technology: Data that has been collected by sensors in the perceptual network layer will be sent to the network layer through secure gate way to be forwarded to the application layer. Such data information must be ensured to be safe, non-hacked or lost in the shipping process, so that, a high level of security shall be installed on the network layer. Network types that can be used include fiber optic cable, 3G/4G network, Wireless Sensor Network (WSN), internet based IP and Bluetooth. IoT can be used to monitor solar power generation (Photovoltaic Generation System), especially, through Wireless Sensor Network (WSN) (Kelly et al., 2013).

Monitoring PV system topology will produce data including panel temperature, solar radiation level, power capacity, data converter, high voltage and current data and fault system. The data will be received by microcontroller in PV controller. Communication in this case still use cable or serial port. The data is then sent to the data center by WSN. Through WSN the monitoring and data storage center will receive real time data information from the sensor instrument to be transmitted by the transmitter data. These data include panel temperature, solar radiation level, power capacity, data converter, high voltage and current data and fault system. The data sent will be received by the receiver data to be sent to the server.

Agent technology: One of the potential methods towards a smart grid is the applications of agents in smart grid operations (Mahmoud et al., 2018; Jassim et al., 2015; Ahmad et al., 2011; Ahmad et al., 2010a). Agents are designed to handle resources autonomously (Mahmoud et al., 2012; Ahmad et al., 2010b; Mahmoud et al., 2016a; Mahmoud et al., 2015; Mahmoud et al., 2013) using agent-based modeling and simulation (Mahmoud et al., 2016b; Mostafa et al., 2013a; Mostafa et al., 2018) which offer flexibility for each resource to collaborate/coordinate/negotiate with each other to achieve the desired goal efficiently (Mostafa et al., 2016, Mostafa et al., 2013b, Mostafa et al., 2014). It was reported by Sendin et al. (2013) that any planned feature of smart grid can be brought into reality by applying intelligent agents as the distributed control building blocks.

\section{CONCLUSION}

The fundamentals of smart grid presented in this study can benefit readers who wish to embark in smart grid research and applications development. Several features of smart grids are discusses which are safe and reliable, self healing, efficient and smart, accomodating, environemntally friendly, priority quality and stability specifications. While the specifications are discussed from three angles components, architecture and areas. The presented components are integrated communication system, modern hardware, modern control and instrumentation, smart software. While the reviewed architecture is users bulk generation, network and communication. Finally, the discussed areas are monitoring and control, integration of information and communication technology, integration of renewable energy and distributed generator, integration of renewable energy and distributed generator, improved transmission application, distribution network management, Advanced Metering Infrastructure (AMI), infrastructure for electric car battery charging, system on the customer side. With smart grid technology, consumers will have full control to manage their electrical energy consumption. Sensor technology and automatic control in the smart grid allow 
the automatic enabling of consumer electrical appliances by taking into account the number of available electrical energies.

\section{ACKNOWLEDGMENTS}

This work is sponsored by Tenaga Nasional Berhad (TNB) under TNB R\&D Seeding Fund Scheme No. TC-RD-18-19. We also gratefully appreciate Universiti Tenaga Nasional \& UNITEN R\&D for securing and managing the fund.

\section{REFERENCES}

Aghaei, J. and M.I. Alizadeh, 2013. Demand response in smart electricity grids equipped with renewable energy sources: A review. Renew. Sustainable Energy Rev., 18: 64-72.

Ahmad, A., M. Zaliman, M. Yusof, M.S. Ahmad, M. Ahmed and A. Mustapha, 2011. Resolving conflicts between personal and normative goals in normative agent systems. Proceedings of the 2011 7th International Conference on Information Technology in Asia, July 12-13, 2011, IEEE, Kuching, Sarawak, Malaysia, pp: 1-6.

Ahmed, M., M.S. Ahmad and M.Z.M. Yusoff, 2010. Mitigating human-human collaboration problems using software agents. Proceedings of the 4th International KES Symposium on Agents and Multi-Agent Systems-Technologies and Application, June 23-25, 2010, Gdynia, Poland, pp: 203-212.

Ahmed, M., M.S. Ahmad and M.Z.M. Yusoff, 2010. Modeling agent-based collaborative process. Proceedings of the 2nd International Conference on Computational Collective Intelligence Technology and Applications, November 10-12, 2010, Taiwan, pp: 296-305.

Ahn, C. and H. Peng, 2013. Decentralized and real-time power dispatch control for an islanded microgrid supported by distributed power sources. Energies, 6: 6439-6454.

Amin, S.M. and B.F. Wollenberg, 2005. Toward a smart grid: Power delivery for the 21st century. IEEE Power Energy Magazine, 3: 34-41.

Baoyun, W., 2009. Review on internet of things. J. Electron. Meas. Instrum., 12: 1-7.

Battaglini, A., J. Lilliestam, A. Haas and A. Patt, 2009. Development of super smart grids for a more efficient utilisation of electricity from renewable sources. J. Cleaner Prod., 17: 911-918.

Dahal, N., O. Abuomar, R. King and V. Madani, 2015. Event stream processing for improved situational awareness in the smart grid. Expert Syst. Appl., 42: 6853-6863.
Deilami, S., A.S. Masoum, P.S. Moses and M.A.S. Masoum, 2011. Real-time coordination of plug-in electric vehicle charging in smart grids to minimize power losses and improve voltage profile. IEEE Trans. Smart Grid, 2: 456-467.

Dibangoye, J., A. Doniec, H. Fakham, F. Colas and X. Guillaud, 2015. Distributed economic dispatch of embedded generation in smart grids. Eng. Appl. Artif. Intell., 44: 64-78.

Evora, J., J.J. Hernandez and M. Hernandez, 2015. A MOPSO method for direct load control in smart grid. Expert Syst. Appl., 42: 7456-7465.

Farhangi, H., 2010. The path of the smart grid. Power Energy Mag., 8: 18-28.

Gangale, F., A. Mengolini and I. Onyeji, 2013. Consumer engagement: An insight from smart grid projects in Europe. Energy Policy, 60: 621-628.

Gao, J., Y. Xiao, J. Liu, W. Liang and C.L.P. Chen, 2012. A survey of communication/networking in Smart Grids. Future Generation Comput. Syst., 28: 391-404.

Gharavi, H. and R. Ghafurian, 2011. Smart grid: The electric energy system of the future. Proc. IEEE., 99: 917-921.

Goulden, M., B. Bedwell, S. Rennick-Egglestone, T. Rodden and A. Spence, 2014. Smart grids, smart users? The role of the user in demand side management. Energy Res. Soc. Sci., 2: 21-29.

Grzonka, D., J. Kolodziej, J. Tao and S.U. Khan, 2015. Artificial neural network support to monitoring of the evolutionary driven security aware scheduling in computational distributed environments. Future Gener. Comput. Syst., 51: 72-86.

Gungor, V.C., B. Lu and G.P. Hancke, 2010. Opportunities and challenges of wireless sensor networks in smart grid. IEEE Trans. Ind. Electr., 57: 3557-3564.

Gungor, V.C., D. Sahin, T. Kocak, S. Ergut, C. Buccella, C. Cecati and G.P. Hancke, 2011. Smart grid technologies: Communication technologies and standards. IEEE Trans. Ind. Inform., 7: 529-539.

Haase, P., 2009. Intelligrid: A smart network of power. EPRI. J., 1: 28-32.

Jarrah, M., M. Jaradat, Y. Jararweh, M. Al-Ayyoub and A. Bousselham, 2015. A hierarchical optimization model for energy data flow in smart grid power systems. Inf. Syst., 53: 190-200.

Jarventausta, P., S. Repo, A. Rautiainen and J. Partanen, 2010. Smart grid power system control in distributed generation environment. Annu. Rev. Control, 34: 277-286.

Jassim, O.A., M.A. Mahmoud and M.S. Ahmad, 2015. A Multi-Agent Framework for Research Supervision Management. In: Distributed Computing and Artificial Intelligence: 12th International Conference, Omatu, S., Q.M. Malluhi, S.R. Gonzalez, G. Bocewicz, E. Bucciarelli, G. Giulioni and F. Iqba (Eds.). Springer, Cham, Switzerland, ISBN: 978-3-319-19637-4, pp: 129-136. 
Kanchev, H., D. Lu, F. Colas, V. Lazarov and B. Francois, 2011. Energy management and operational planning of a microgrid with a PV-based active generator for smart grid applications. IEEE. Trans. Ind. Electron., 58: 4583-4592.

Kelly, S.D.T., N.K. Suryadevara and S.C. Mukhopadhyay, 2013. Towards the implementation of IoT for environmental condition monitoring in homes. IEEE. Sens. J., 13: 3846-3853.

Kilic, N. and V.C. Gungor, 2013. Analysis of low power wireless links in smart grid environments. Comput. Networks, 57: 1192-1203.

Kim, B.Y., K.K. Oh and H.S. Ahn, 2015. Coordination and control for energy distribution in distributed grid networks: Theory and application to power dispatch problem. Control Eng. Pract., 43: 21-38.

Li, L., H. Xiaoguang, C. Ke and H. Ketai, 2011. The applications of WiFi-based wireless sensor network in internet of things and smart grid. Proceedings of the 2011 6th IEEE International Conference on Industrial Electronics and Applications, June 21-23, 2011, IEEE, Beijing, China, pp: 789-793.

Ling, A.P.A. and M. Masao, 2011. Selection of model in developing information security criteria on smart grid security system. Proceedings of the 2011 IEEE 9th International Symposium on Parallel and Distributed Processing with Applications Workshops, May 26-28, 2011, IEEE, Busan, South Korea, pp: 91-98.

Liu, S., Y. Hou, C.C. Liu and R. Podmore, 2013. The healing touch: Tools and challenges for smart grid restoration. IEEE. Power Energy Mag., 12: 54-63.

Mahmoud, M., M.S. Ahmad and M.Z.M. Yusoff, 2016. Development and implementation of a technique for norms-adaptable agents in open multi-agent communities. J. Syst. Sci. Complexity, 29: 1519-1537.

Mahmoud, M.A., A. Mustapha, M.S. Ahmad, A. Ahmad, M.Z.M. Yusoff and N.H.A. Hamid, 2013. Potential Norms Detection in Social Agent Societies. In: Distributed Computing and Artificial Intelligence, Advances in Intelligent Systems and Computing, Omatu, S., H. Bersini, J.M. Corchado, S. Rodriguez, P. Pawlewski and E. Bucciarelli (Eds.). Springer, Germany, ISBN: 978-3-319-07593-8, pp: 419-428.

Mahmoud, M.A., M.S. Ahmad and M.Z.M. Yusoff, 2016. A norm assimilation approach for multi-agent systems in heterogeneous communities. Proceedings of the Asian Conference on Intelligent Information and Database Systems, March 14-16, 2016, Springer, Berlin, Germany, pp: 354-363.
Mahmoud, M.A., M.S. Ahmad, A. Ahmad, M.Z.M. Yusoff and A. Mustapha, 2012. A norms mining approach to norms detection in multi-agent systems. Proceedings of the International Conference on Computer and Information Sciences, Volume 1, June 12-14, 2012, Kuala Lumpeu, pp: 458-463.

Mahmoud, M.A., M.S. Ahmad, M.Z.M. Yusoff and A. Idrus, 2015. Automated Multi-Agent Negotiation Framework for the Construction Domain. In: Distributed Computing and Artificial Intelligence: 12th International Conference, Omatu, S., Q.M. Malluhi, S.R. Gonzalez, G. Bocewicz, E. Bucciarelli, G. Giulioni and F. Iqba (Eds.). Springer, Cham, Switzerland, ISBN: 978-3-319-19637-4, pp: 203-210.

Mahmoud, M.A., R. Ramli, F. Azman and J. Grace, 2018. A development methodology framework of smart manufacturing systems (Industry 4.0). Moroccan Youth Social Entrepreneurs Camp, Rabat, Morocco.

Momoh, J.A., 2009. Smart grid design for efficient and flexible power networks operation and control. Proceedings of the 2009 IEEE/PES Power Systems Conference and Exposition, March 15-18, 2009, IEEE, Seattle, Washington, USA., pp: 1-8.

Mostafa, S.A., M.S. Ahmad, A. Ahmad, M. Annamalai and A. Mustapha, 2014. A Dynamic Measurement of Agent Autonomy in the Layered Adjustable Autonomy Model. In: Recent Developments in Computational Collective Intelligence, Badica, A., B. Trawinski and N.T. Nguyen (Eds.). Springer, Cham, Switzerland, ISBN: 978-3-319-01786-0, pp: 25-35.

Mostafa, S.A., M.S. Ahmad, A. Ahmad, M. Annamalai and S.S. Gunasekaran, 2016. A flexible human-agent interaction model for supervised autonomous systems. Proceedings of the 2016 2nd International Symposium on Agent, Multi-Agent Systems and Robotics (ISAMSR), August 23-24, 2016, IEEE, Bangi, Malaysia, pp: 106-111.

Mostafa, S.A., M.S. Ahmad, M. Annamalai, A. Ahmad and S. S. Gunasekaran, 2013. A Conceptual Model of Layered Adjustable Autonomy. In: Advances in Information Systems and Technologies, Rocha, A., A.M. Correia, T. Wilson and K.A. Stroetmann (Eds.). Springer, Berlin, Germany, ISBN: 978-3-642-36980-3, pp: 619-630.

Mostafa, S.A., M.S. Ahmad, M. Annamalai, A. Ahmad and S. S. Gunasekaran, 2013. A Dynamically Adjustable Autonomic Agent Framework. In: Advances in Information Systems and Technologies, Rocha, A., A.M. Correia, T. Wilson and K.A. Stroetmann (Eds.). Springer, Berlin, Germany, ISBN: 978-3-642-36980-3, pp: 631-642. 
Mostafa, S.A., R. Darman, S.H. Khaleefah, A. Mustapha, N. Abdullah and H. Hafit, 2018. A general framework for formulating adjustable autonomy of multi-agent systems by fuzzy logic. Proceedings of the KES International Symposium on Agent and Multi-Agent Systems: Technologies and Applications, June 20-22, 2018, Springer, Cham, Switzerland, pp: 23-33.

NIST., 2010. NIST framework and roadmap for smart grid interoperability standards. National Institute of Standards and Technology, Gaithersburg, Maryland. https://www.nist.gov/sites/default/files/documents/ public_affairs/releases/smartgrid_interoperability_f inal.pdf

Rohjans, S., C. Danekas and M. Uslar, 2012. Requirements for smart grid ICT-architectures. Proceedings of the 2012 3rd IEEE PES Innovative Smart Grid Technologies Europe (ISGT Europe'12), October 14-17, 2012, IEEE, Berlin, Germany, pp: 1-8.
Sendin, A., I. Berganza, A. Arzuaga, X. Osorio, I. Urrutia and P. Angueira, 2013. Enhanced operation of electricity distribution grids through smart metering PLC network monitoring, analysis and grid conditioning. Energies, 6: 539-556.

Siano, P., 2014. Demand response and smart grids-A survey. Renewable Sustainable Energy Rev., 30: 461-478.

Wang, C. and P. Li, 2010. Development and challenges of distributed generation, the micro-grid and smart distribution system. Autom. Electr. Power Syst., Vol. 2, No. 4.

Wang, P., H. Hou, X. He, C. Wang, T. Xu and Y. Li, 2015. Survey on application of wireless sensor network in smart grid. Procedia Comput. Sci., 52: 1212-1217.

Yun, M. and B. Yuxin, 2010. Research on the architecture and key technology of Internet of Things (IoT) applied on smart grid. Proceedings of the 2010 International Conference on Advances in Energy Engineering (ICAEE), June 19-20, 2010, IEEE, New York, USA., pp: 69-72. 